Article

\title{
The Auxiliary Effect of Copper Ions on the Depressant Effect of Sodium Thioglycolate in Chalcopyrite Flotation
}

\author{
Chonghui Zhang ${ }^{1}$, Tingshu He ${ }^{1, *}$, Wei Chen ${ }^{1,2, *} \mathbb{C}$, Xianzhong $\mathrm{Bu}^{1}$, Sen Wang ${ }^{1}$ and \\ Xiaozhen Tian ${ }^{1}$ \\ 1 School of Resources Engineering, Xi'an University of Architecture and Technology, Xi'an 710055, China; \\ zhangchonghui@xauat.edu.cn (C.Z.); buxianzhong@xauat.edu.cn (X.B.); wangsne@163.com (S.W.); \\ tiaxiz@xauat.edu.cn (X.T.) \\ 2 State Key Laboratory of Mineral Processing, BGRIMM Technology Group, Beijing 100160, China \\ * Correspondence: hetingshu@xauat.edu.cn (T.H.); csuchenwei@csu.edu.cn (W.C.); \\ Tel.: +86-029-8220-3408 (T.H. \& W.C.)
}

Received: 16 January 2020; Accepted: 10 February 2020; Published: 12 February 2020

\begin{abstract}
Sodium thioglycolate is a chalcopyrite depressant, but its depressant effect is weak. The paper investigated the effect of $\mathrm{CuSO}_{4}$ on the depressant performance of sodium thioglycolate towards chalcopyrite through flotation tests, Zeta potential measurements, X-ray photoelectron spectroscopy (XPS) analyses and Fourier-transform infrared (FTIR) spectra measurements. It was found that copper ions could improve the depressant effect of sodium thioglycolate on chalcopyrite. The results showed that copper ions could adsorb on the surface of chalcopyrite and form mixed copper sulfide and cupric oxides/hydroxides adsorption layers. As a result, the mineral composition on the chalcopyrite surface was changed. With sodium thioglycolate treatment, the Zeta potential and the adsorption sites of chalcopyrite surface were both increased, and the hydrophobic substance $\mathrm{Sn}^{2-} / \mathrm{S}^{0}$ concentration was decreased. The electrostatic repulsion of chalcopyrite surface with sodium thioglycolate was also decreased, which made the sodium thioglycolate interact with chalcopyrite more easily. The more active sites could adsorb more sodium thioglycolate, which improved the hydrophilia of chalcopyrite. At the same time, the decrease of $S^{2-} / S^{0}$ concentration could further improve the hydrophilia of chalcopyrite. The results show that the copper ions could exhibit auxiliary effect with sodium thioglycolate and could further enhance the depressant effect of sodium thioglycolate on the chalcopyrite flotation. This paper provides new insights into the depression of chalcopyrite flotation by sodium thioglycolate.
\end{abstract}

Keywords: flotation; chalcopyrite; sodium thioglycolate; copper ions; depressant

\section{Introduction}

Chalcopyrite $\left(\mathrm{CuFeS}_{2}\right)$ is the most widely distributed copper mineral in the nature, accounting for about $70 \%$ of the Earth's whole copper resources [1]. Chalcopyrite often coexists and is associated with other nonferrous metal sulfide, which brings difficulties to its utilization. The recovery of chalcopyrite is mainly realized by the flotation method. In the flotation separation operations, the main depressants of chalcopyrite used are cyanide [2], sodium sulfides [3], and thioglycolic acids [4]. The effect of cyanide depressed chalcopyrite is the best, but it is highly toxic. In addition, with the improvement of environmental protection awareness in China, cyanide will be gradually eliminated. Sodium sulfide could easily oxidize, and its concentration or dosage in flotation is too high. The depressant effect of thioglycolic acids is worse than that of the former two, but it has the advantages of less pollution, easy control, and high selectivity, giving it certain application in some flotation plants. 
Thioglycolic acids, including thioglycolic acid (TGA) and sodium thioglycolate (STG), are organic depressants. The mercapto group (-SH) of TGA or STG reacts with copper, and then TGA or STG adsorbs onto the mineral surface [4]. The carboxyl group $(-\mathrm{COOH})$ is hydrophilic and could form hydrophilic membrane layer, which could enhance hydrophilic property of the mineral and prevent collector adsorption on the mineral surface. It is generally accepted that the effect of flotation reagent can be changed by metal ions [5-11]. Copper sulphate, as an activator, has been used in industrial flotation for a long time, and is mainly used for the flotation of nonferrous sulfide [5]. It has been proved that adding $\mathrm{CuSO}_{4}$ can significantly improve the recovery of valuable minerals, especially sphalerite. Inactivated sphalerite interacts weakly with xanthate collectors. When copper sulfate activates sphalerite, the $\mathrm{Cu}$ ion is exchanged with the $\mathrm{Zn}$ ion of sphalerite, which forms the surface of copper sulfide and enhances the adsorption of collector [6]. Unlike sphalerite, inactivated pyrite responds well to xanthate collector, and the copper sulphate activation of pyrite follows a different mechanism from that of sphalerite. The mechanism is not an ion exchange activation mechanism, but the adsorption of copper on the active sulfur site on only the surface [7]. Sodium sulfide is used as a depressant, and the addition of $\mathrm{Cu}^{2+}$ can obviously promote the effect of depressing chalcopyrite. $\mathrm{CuOH}^{+}$and $\mathrm{Cu}(\mathrm{OH})_{2}$ are adsorbed on the mineral surface after the hydrolysis of $\mathrm{Cu}^{2+}$ and provide more reactive sites for the depressant [8]. Also, the interaction between butyl xanthate and the surface of unactivated stibnite is weak, and the flotation effect is poor. $\mathrm{Pb}^{2+}$ can be adsorbed on the stibnite surface, and the lead atoms on the surface of stibnite can interact with butyl xanthate further. The adsorption energy of butyl xanthate on the surface of lead activation is much lower than that on the surface of nonactivation [9]. This indicates that metal ions, especially copper ions, can change the surface properties of sulphide minerals, and then affect the amounts of active adsorption sites with flotation reagents and the flotation effect. However, there is little research showing that copper ions can enhance the depressant effect of sodium thioglycolate on chalcopyrite.

In this study, the mechanism of copper ions strengthening the sodium thioglycolate's depressing chalcopyrite effect was studied by micro-flotation tests, Zeta potential measurements, X-ray photoelectron spectroscopy (XPS) measurements, and Fourier transform infrared (FTIR) spectra measurements.

\section{Materials and Methods}

\subsection{Mineral Samples and Reagents}

The chalcopyrite sample was obtained from Guangxi, China. The pure chalcopyrite sample was handpicked and further crushed and dry-sieved to $-2 \mathrm{~mm}$ through a jaw crusher and a laboratory roll crusher in turn. The -2-mm-size fractions were stored for subsequent grinding, flotation, Zeta potential measurements, XPS measurements, and FTIR study. The purity of the chalcopyrite sample was $96.15 \%$ according to its X-ray diffraction results (see Figure 1) and chemical analysis (see Table 1).

The butyl xanthate (BX) and pine oil used in this research were purchased from Zhuzhou Flotation Reagents Factory, Zhuzhou, China and were both industrial grade. They were used as the collector and frother, respectively. Copper sulfate $\left(\mathrm{CuSO}_{4}\right)$ was bought from Tianjing Kermil Chemical Reagents Development Centre, Tianjin, China, and was analytical reagent (AR) grade. $\mathrm{CuSO}_{4}$ was used as flotation modifier. Sodium thioglycolate (STG), sulphuric acid $\left(\mathrm{H}_{2} \mathrm{SO}_{4}\right)$, and sodium hydroxide $(\mathrm{NaOH})$ were all obtained from Aladdin Industrial Corporation, Shanghai, China, and were all AR grade. Sodium thioglycolate is a kind of white powder. It easily dissolves in water and is used as depressant. Sulphuric acid $\left(\mathrm{H}_{2} \mathrm{SO}_{4}\right)$ and sodium hydroxide $(\mathrm{NaOH})$ were used as $\mathrm{pH}$ regulators.

Table 1. Chemical composition of the chalcopyrite sample used in this research.

\begin{tabular}{ccccc}
\hline Chemical Composition & $\mathbf{C u}$ & $\mathbf{F e}$ & $\mathrm{S}$ & Other \\
\hline Content $(\%)$ & 33.23 & 29.34 & 33.58 & 3.85 \\
\hline
\end{tabular}




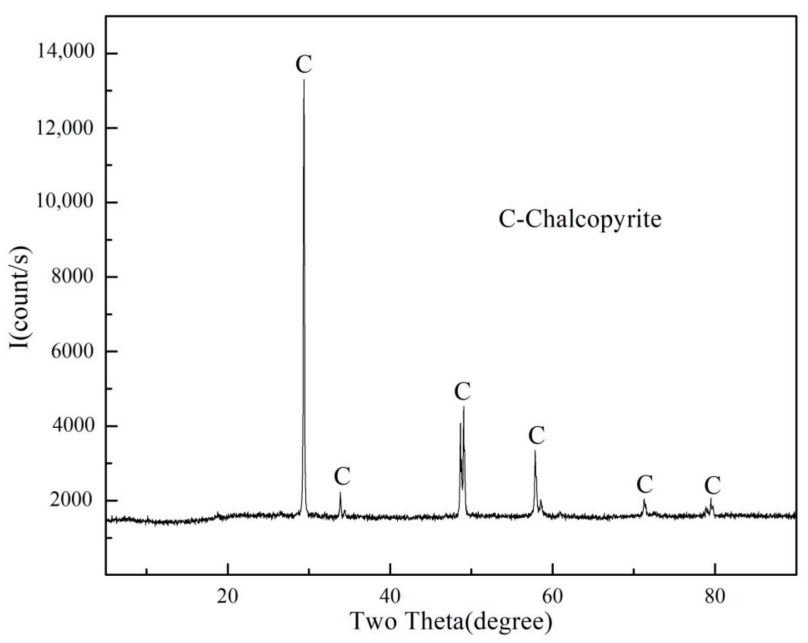

Figure 1. XRD spectra of the chalcopyrite sample.

\subsection{Micro-Flotation Tests}

Before micro-flotation tests, the stored -2-mm-size chalcopyrite sample were ground to $-74 \mu \mathrm{m}$ for each micro-flotation tests using an agate planetary ball mill (XDQM-2L, Lianyungang Chunlong Experimental Instrument Co., Ltd., Lianyungang, China).

Micro-flotation tests of chalcopyrite sample were carried out in a plexiglass flotation cell with a volume of $50 \mathrm{~mL}$ in air conditioning by an inflatable hanging slot flotation machine (XFGCII 5-35 g, Jilin Prospecting Machinery Factory, Changchun, China). First, $2 \mathrm{~g}$ of the chalcopyrite sample was mixed with $45 \mathrm{~mL}$ of distilled water in the flotation cell. The $\mathrm{pH}$ regulator, copper sulfate (if needed), depressant (if needed), collector, and frother were added into the flotation cell in sequence and conditioned for $3 \mathrm{~min}$ for each reagent. Then, the flotation began, and the flotation time was $3 \mathrm{~min}$. After flotation, the flotation concentrates and tailings were filtered, dried, and weighted, and recoveries were calculated.

\subsection{Zeta Potential Measurements}

Before each measurement, the stored -2 -mm-size chalcopyrite sample were ground to $-2 \mu \mathrm{m}$ for each Zeta potential measurement using an agate planetary ball mill.

The Zeta potentials of chalcopyrite samples were measured using a Zeta Potential Analyzer (Delsa 440sx, Beckman Coulter, Inc., Fullerton, CA, USA). For each Zeta potential measurement, $0.03 \mathrm{~g}$ of the chalcopyrite sample was mixed with $30 \mathrm{~mL}$ of $1-\mathrm{mmol} \mathrm{KNO}_{3}$ solution in a $50-\mathrm{mL}$ beaker and, the desired concentrations of the flotation reagents were added. The concentration of copper sulfate was $1 \times 10^{-3} \mathrm{~mol} / \mathrm{L}$ and sodium thioglycolate was $1.5 \times 10^{-3} \mathrm{~mol} / \mathrm{L}$, respectively. The $\mathrm{pH}$ of mineral suspension was adjusted by adding of either $10 \mathrm{M}$ of $\mathrm{NaOH}$ or $\mathrm{H}_{2} \mathrm{SO}_{4}$, and the $\mathrm{pH}$ range was 8-12 in the studies. After stirring for $15 \mathrm{~min}$ using a magnetic stirrer and standing of $10 \mathrm{~min}$, the fine mineral particles were sucked into electrophoresis cell for measurement from the top of the resultant suspension. Each sample was conducted at least three times measurement independently, with a typical variation of $\pm 5 \mathrm{mV}$. The average value was taken as the final result.

\subsection{XPS Measurements}

Before each measurement, the stored -2-mm-size chalcopyrite sample were ground to $-74 \mu \mathrm{m}$ for each XPS measurement using an agate planetary ball mill.

For each XPS measurement, $2 \mathrm{~g}$ of the chalcopyrite sample was mixed with $45 \mathrm{~mL}$ of distilled water in a 50-mL beaker, and desired concentrations of the flotation reagents were added. The concentration of copper sulfate was $1 \times 10^{-3} \mathrm{~mol} / \mathrm{L}$ and sodium thioglycolate was $1.5 \times 10^{-3} \mathrm{~mol} / \mathrm{L}$, respectively. 
The $\mathrm{pH}$ of mineral suspension was adjusted by adding of either $10 \mathrm{M}$ of $\mathrm{NaOH}$ or $\mathrm{H}_{2} \mathrm{SO}_{4}$. After stirring for 15 min using a magnetic stirrer, the pulp was filtrated and stored for XPS analysis.

The XPS spectra analysis of chalcopyrite before and after treatment with flotation reagents were recorded on a Perkin-Elmer Physical Electronics Division (PHI) 5100 spectrometer (Thermo Scientific ESCALAB, Thermo Fisher Scientific, Waltham, MA, USA) using K $\alpha$ X-ray source at $200 \mathrm{~W}$ and pass energy of $75 \mathrm{eV}$. The samples were first measured in survey mode, and then the high-resolution of $\mathrm{C} 1 \mathrm{~s}, \mathrm{Cu} 2 \mathrm{p}$, and S 2p were scanned. The XPS spectra were analyzed and fitted by the Thermo Avantage software. The $\mathrm{C} 1 \mathrm{~s}$ binding energy at $284.8 \mathrm{eV}$ were selected as a standard to calibrate the binding energy.

\subsection{FTIR Spectra Measurements}

Before each measurement, the stored -2 -mm-size chalcopyrite sample was ground to $-74 \mu \mathrm{m}$ for each FTIR spectrum measurement using an agate planetary ball mill.

For each FTIR spectrum measurement, $2 \mathrm{~g}$ of the chalcopyrite sample was mixed with $45 \mathrm{~mL}$ of distilled water in a 50-mL beaker, and desired concentrations of the flotation reagents were added. The concentration of copper sulfate was $1 \times 10^{-3} \mathrm{~mol} / \mathrm{L}$ and sodium thioglycolate was $1.5 \times 10^{-3} \mathrm{~mol} / \mathrm{L}$, respectively. The $\mathrm{pH}$ of mineral suspension was adjusted by adding of either $10 \mathrm{M}$ of $\mathrm{NaOH}$ or $\mathrm{H}_{2} \mathrm{SO}_{4}$. After stirring for 15 min using a magnetic stirrer, the pulp was filtrated and rinsed two or three times using the corresponding $\mathrm{pH}$ stock solutions. The samples were stored in a vacuum desiccator at room temperature for FTIR spectra analysis.

The FTIR spectra analysis of chalcopyrite before and after treatment with flotation reagents were recorded on an Fourier Transform Infrared Spectrometer (IRAffinity-1, shimadzu, Kyoto, Japan) by potassium bromide $(\mathrm{KBr})$ reflection method. The spectra were recorded at a $2 \mathrm{~cm}^{-1}$ resolution in the $4000-400 \mathrm{~cm}^{-1}$ region.

\section{Results}

\subsection{Micro-Flotation Results}

The effect of STG on the chalcopyrite flotation was studied, and then the auxiliary actions of the copper ions on the depressant effect of STG on the chalcopyrite flotation were investigated. The results are shown in Figures 2-4, respectively.

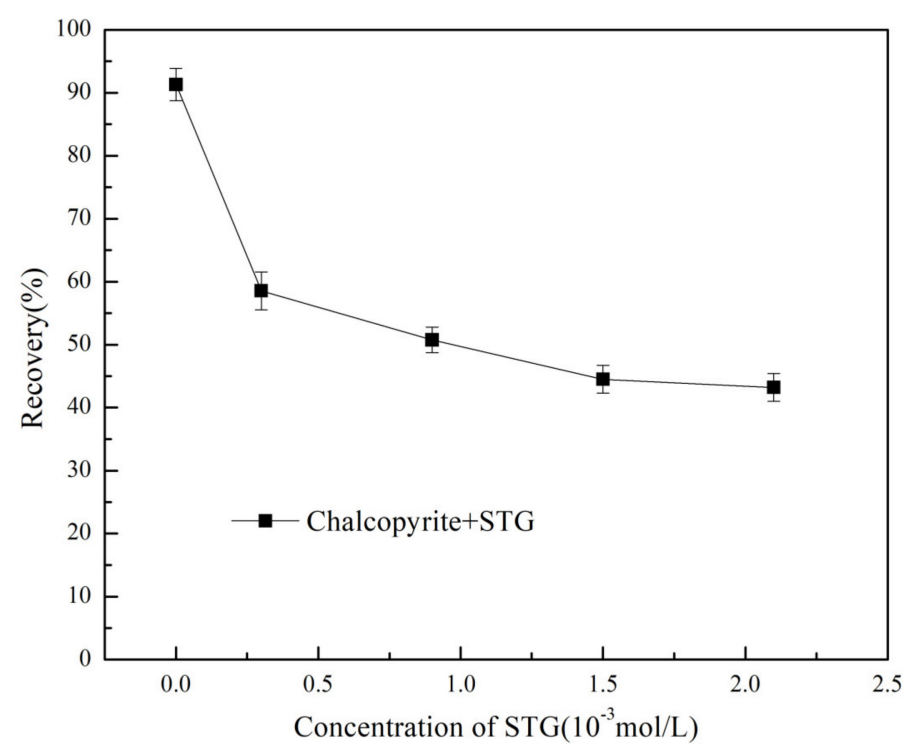

Figure 2. The flotation recovery of chalcopyrite under different sodium thioglycolate (STG) concentrations; $\mathrm{c}(\mathrm{BX})=1 \times 10^{-3} \mathrm{~mol} / \mathrm{L}, \mathrm{pH}=10$. 
As shown in Figure 2, the floatability of chalcopyrite decreased as the STG dosage increased. When the STG dosage increased from $0 \mathrm{~mol} / \mathrm{L}$ to $2.0 \times 10^{-3} \mathrm{~mol} / \mathrm{L}$, the chalcopyrite recovery decreased from $92 \%$ to around $45 \%$. The decreased recovery indicates that the STG exhibited some depressant effect on the chalcopyrite flotation. However, the inhibition of chalcopyrite using STG alone was not efficient, as shown by the stable existed recovery value ( $>40 \%)$ when STG concentration continued to rise.

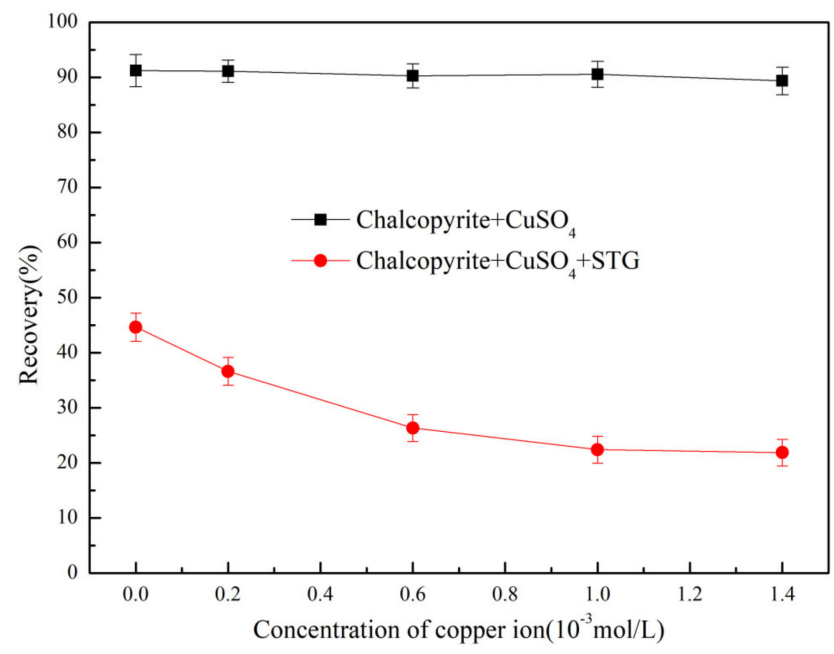

Figure 3. The flotation recovery of chalcopyrite under different $\mathrm{Cu}^{2+}$ concentrations; $\mathrm{c}(\mathrm{STG})=1.5 \times$ $10^{-3} \mathrm{~mol} / \mathrm{L}, \mathrm{c}(\mathrm{BX})=1 \times 10^{-3} \mathrm{~mol} / \mathrm{L}, \mathrm{pH}=10$.

Figure 3 shows the depressant effect of copper ions on the chalcopyrite flotation in the presence and absence of STG. In the absence of STG, the chalcopyrite flotation was merely influenced as copper ions dosage increased, indicating that the copper ions had no effect on the chalcopyrite flotation. In the presence of STG, the chalcopyrite recovery witnessed a big decrease (from $44 \%$ to around $22 \%$ ) when the copper ions dosage increased from $0 \mathrm{~mol} / \mathrm{L}$ to $1.4 \times 10^{-3} \mathrm{~mol} / \mathrm{L}$. The decreased recovery indicates that the copper ions exhibited an auxiliary depressant effect on the chalcopyrite flotation with STG and that the inhibition was quite efficient.

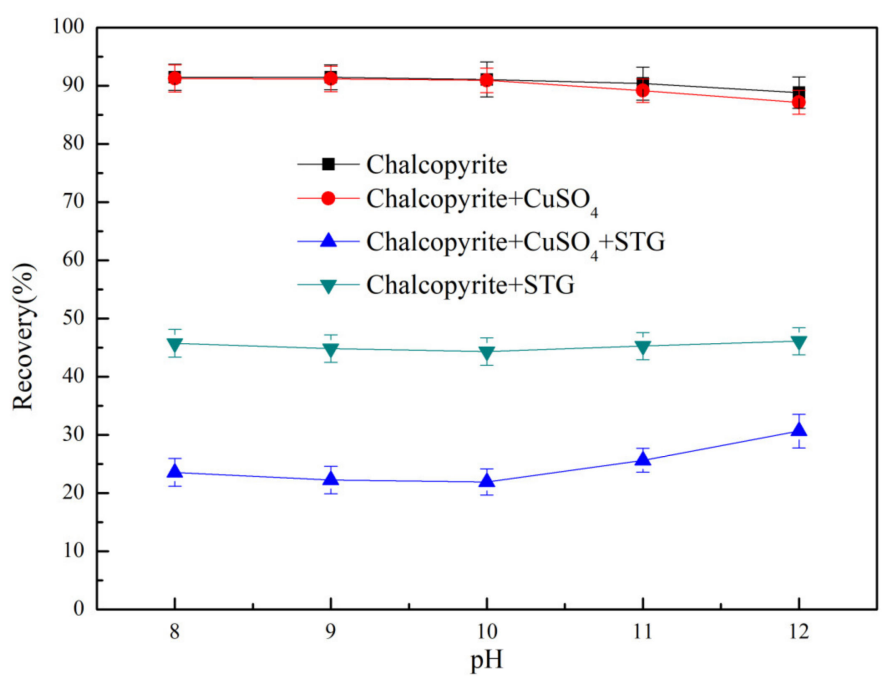

Figure 4. The flotation recovery of chalcopyrite under different $\mathrm{pH}$ values; $\mathrm{c}\left(\mathrm{Cu}^{2+}\right)=1 \times 10^{-3} \mathrm{~mol} / \mathrm{L}$, $\mathrm{c}(\mathrm{STG})=1.5 \times 10^{-3} \mathrm{~mol} / \mathrm{L}, \mathrm{c}(\mathrm{BX})=1 \times 10^{-3} \mathrm{~mol} / \mathrm{L}$.

Figure 4 shows the flotation performance of chalcopyrite under different reagent schemes. It was first noted that chalcopyrite was well floated using collector BX (or using BX and a copper ions scheme) 
in the whole $\mathrm{pH}$ range tested. The flotation recovery with both reagent schemes remained nearly unchanged and above $90 \%$. With treatment of $1.5 \times 10^{-3} \mathrm{~mol} / \mathrm{L} \mathrm{STG}+1 \times 10^{-3} \mathrm{~mol} / \mathrm{L} \mathrm{BX}$ scheme, the chalcopyrite recovery was decreased to $40-50 \%$ in the $\mathrm{pH}$ range of $8-12$. However, with the treatment of $1 \times 10^{-3} \mathrm{~mol} / \mathrm{L} \mathrm{Cu}^{2+}+1.5 \times 10^{-3} \mathrm{~mol} / \mathrm{L} \mathrm{STG}+1 \times 10^{-3} \mathrm{~mol} / \mathrm{L} \mathrm{BX}$ scheme, the chalcopyrite flotation was well depressed in the $\mathrm{pH}$ range of 8-10, indicating that the $\mathrm{Cu}^{2+}$ exhibited auxiliary effect on the depressant effect of STG on the chalcopyrite flotation.

To define the auxiliary depressant effect of $\mathrm{Cu}^{2+}$ and STG on chalcopyrite flotation, the surface property analysis including surface potential, XPS, and FTIR of chalcopyrite particles with similar flotation reagent scheme treatment was conducted.

\subsection{Zeta Potential Measurement Results}

In this study, the Zeta potentials of chalcopyrite with different reagent treatment were used to evaluate the relative adsorption strength of certain reagents. The Zeta potentials of chalcopyrite particles under corresponding flotation conditions as studied in Section 3.1 were measured, and the results are shown in Figure 5.

For bare chalcopyrite, the Zeta potential was negatively charged in the whole $\mathrm{pH}$ range studied. As $\mathrm{pH}$ increased, the Zeta potential of chalcopyrite decreased from $-14.65 \mathrm{mV}(\mathrm{pH} 8.0)$ to $-34.63 \mathrm{mV}$ ( $\mathrm{pH}$ 12.0). With copper ion treatment, the Zeta potential of chalcopyrite increased in the whole $\mathrm{pH}$ range studied. The rise of the Zeta potential showed that copper ions adsorbed on the chalcopyrite surface and changed character of chalcopyrite surface. Meanwhile, the electrostatic repulsion of chalcopyrite surface with STG was decreased, which made the STG interact with chalcopyrite easier.

With the STG treatment, the Zeta potential of chalcopyrite decreased in the whole $\mathrm{pH}$ range studied. The fall of the Zeta potential shows that STG can chemically adsorb on the chalcopyrite surface. Compared with the copper ion treatment, with the copper ion and STG treatment, the Zeta potential of chalcopyrite decreased again. Compared with the Zeta potential of chalcopyrite in the presence and absence of STG, the Zeta potential decreased by around $4.0 \mathrm{mV}(\mathrm{pH} 8.0), 4.0 \mathrm{mV}(\mathrm{pH} 9.0)$, $3.0 \mathrm{mV}$ ( $\mathrm{pH} 10.0), 1.3 \mathrm{mV}$ (pH 11.0), and $-1.6 \mathrm{mV}$ (pH 12.0). Compared with the Zeta potential of copper-treated chalcopyrite in the presence and absence of STG, the Zeta potential decreased by

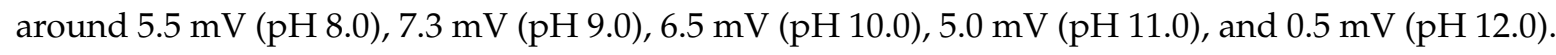
The decrease of Zeta potential was further expanded with copper ions treatment and became smaller as the $\mathrm{pH}$ increased over 10, indicating that copper-treated chalcopyrite surface adsorbed more STG and improved the depressant effect at $\mathrm{pH} 8-10$.

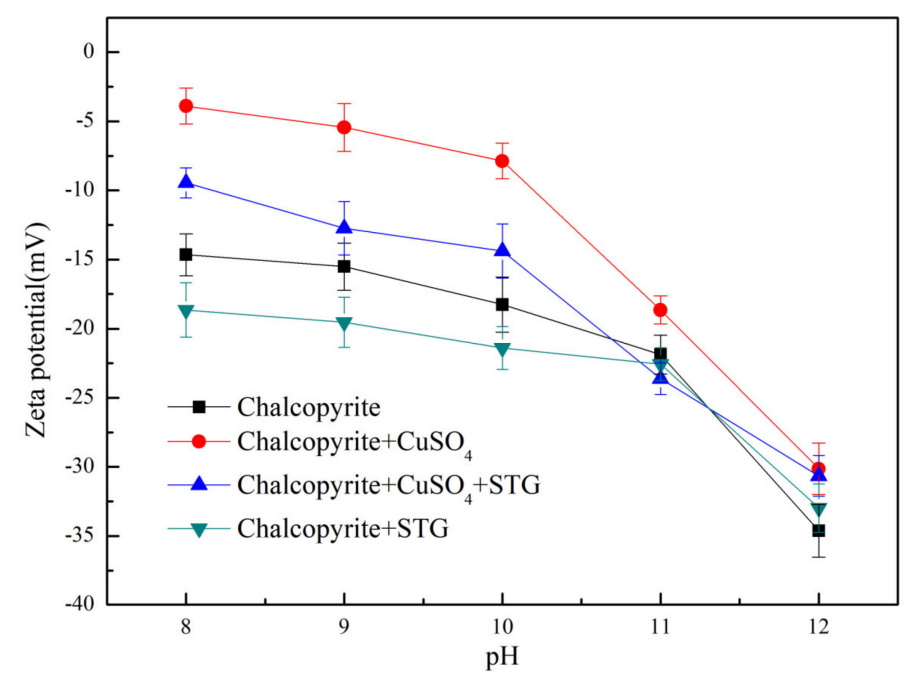

Figure 5. The Zeta potential of chalcopyrite under different $\mathrm{pH}$ values; $\mathrm{c}\left(\mathrm{Cu}^{2+}\right)=1 \times 10^{-3} \mathrm{~mol} / \mathrm{L}$, $\mathrm{c}(\mathrm{STG})=1.5 \times 10^{-3} \mathrm{~mol} / \mathrm{L}, \mathrm{c}(\mathrm{BX})=1 \times 10^{-3} \mathrm{~mol} / \mathrm{L}$. 


\subsection{X-Ray Photoelectron Spectroscopy (XPS) Results}

In order to explain the phenomenon that copper ions could enhance the depressant effect of STG on chalcopyrite, the X-ray photoelectron spectroscopy of chalcopyrite samples with and without the treatment of corresponding flotation reagents schemes was measured. The results are shown in Tables 2 and 3 and Figures 6 and 7, respectively.

Figure 6 shows the $S 2 p$ spectra of the chalcopyrite with treatment of different flotation reagents. The XPS bands at 161.2-161.4 eV were attributed to surface monosulfide $S^{2-}[6,12-15]$. The XPS bands at 162.4-162.8 eV were attributed to the disulfide species $S_{2}{ }^{2-}$ by the oxidation process of $\mathrm{S}^{2-}$ on the chalcopyrite surface [6,12-15], and the XPS bands at 163.3-164.0 eV were the results of the polysulfide and elemental sulfur $S_{n}{ }^{2-} / S^{0}$ that were formed in the oxidation operations [6,12-15]. With the copper ion treatment (see Figure $6 \mathrm{~b}$ ), it can be seen that a new $S$ 2p3/2 peak appeared at $168.83 \mathrm{eV}$, which is mostly attributed to the adsorption of the $\mathrm{SO}_{4}^{2-}$ on the chalcopyrite surface $[14,16]$. The $\mathrm{S}_{\mathrm{n}}{ }^{2-} / \mathrm{S}^{0}$ concentration decreased largely from $22.08 \%$ to $11.96 \%$, indicating that the added $\mathrm{CuSO}_{4}$ had successfully prevented the formation of $S_{n}{ }^{2-} / S^{0}$. At the same time, the $S^{2-}$ concentration also decreased from $63.52 \%$ to $47.68 \%$, showing that the hydrophobicity of the chalcopyrite was also largely influenced. The above decreases strongly prove that the mineral composition on the surface of chalcopyrite changed with the $\mathrm{CuSO}_{4}$ treatment. Figure $6 \mathrm{c}$ shows the XPS band of the chalcopyrite with the treatment of STG. It can be seen that a new band appeared at $162.03 \mathrm{eV}$ [17], suggesting that the STG adsorbed on the particle surface, mainly through the C-SCu bond. However, with the $\mathrm{CuSO}_{4}$ and STG treatment, the concentrations of the sulfur species and C-SCu bond concentration significantly increased from $18.49 \%$ to $39.36 \%$, as shown in Figure $6 \mathrm{~d}$. The results indicate that the added copper ions exhibited an auxiliary effect with STG on the chalcopyrite flotation.
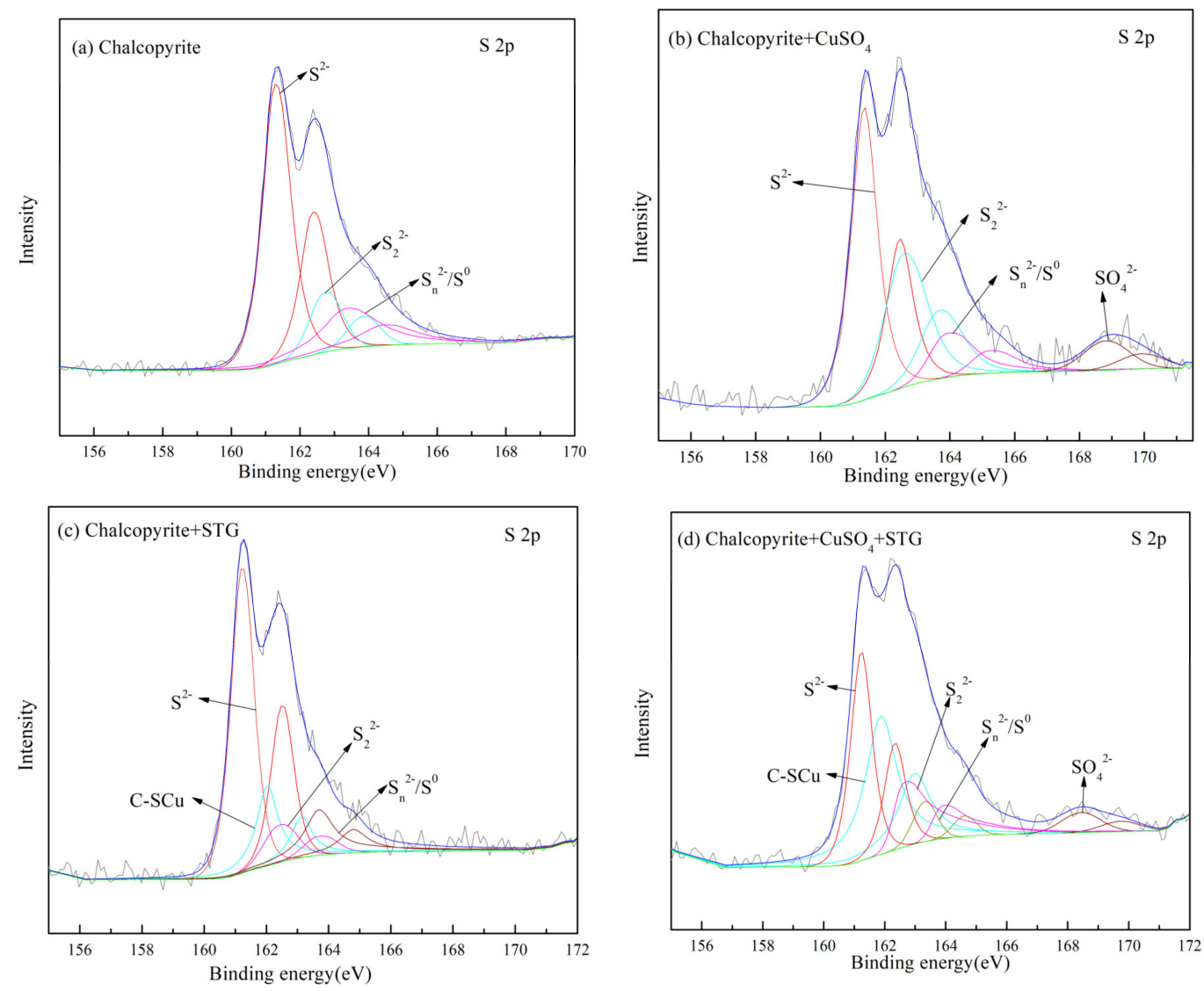

Figure 6. S 2p XPS spectra of chalcopyrite (a), chalcopyrite $+\mathrm{CuSO}_{4}(\mathbf{b})$, chalcopyrite $+\mathrm{STG}(\mathbf{c})$ and chalcopyrite $+\mathrm{CuSO}_{4}+\mathrm{STG}(\mathrm{d}) ; \mathrm{c}\left(\mathrm{CuSO}_{4}\right)=1 \times 10^{-3} \mathrm{~mol} / \mathrm{L}, \mathrm{c}(\mathrm{STG})=1.5 \times 10^{-3} \mathrm{~mol} / \mathrm{L}$. 
Table 2. The parameters and assignment of high-resolution S 2p XPS spectra.

\begin{tabular}{|c|c|c|c|c|}
\hline Species & Binding Energy/eV & FWHM/eV & Percentage $/ \%$ & Assignment \\
\hline \multirow{3}{*}{ Chalcopyrite } & $161.27 / 162.37$ & 0.88 & 63.52 & $\mathrm{~S}^{2-}$ \\
\hline & $162.75 / 163.85$ & 1.1 & 14.39 & $\mathrm{~S}_{2}{ }^{2-}$ \\
\hline & $163.34 / 164.44$ & 1.68 & 22.08 & $S_{n}{ }^{2-} / S^{0}$ \\
\hline \multirow{4}{*}{ Chalcopyrite $+\mathrm{Cu}$} & $161.35 / 162.45$ & 0.98 & 47.68 & $\mathrm{~S}^{2-}$ \\
\hline & $162.58 / 163.68$ & 1.46 & 33.00 & $\mathrm{~S}_{2}{ }^{2-}$ \\
\hline & $163.92 / 165.22$ & 1.25 & 11.98 & $\mathrm{~S}^{2-} / \mathrm{S}^{0}$ \\
\hline & $168.83 / 169.93$ & 1.65 & 7.36 & $\mathrm{SO}_{4}^{2-}$ \\
\hline \multirow{4}{*}{ Chalcopyrite + STG } & $161.21 / 162.49$ & 0.86 & 55.63 & $\mathrm{~S}^{2-}$ \\
\hline & $162.03 / 163.13$ & 0.82 & 18.49 & C-SCu \\
\hline & $162.40 / 163.70$ & 1.17 & 9.27 & $\mathrm{~S}_{2}{ }^{2-}$ \\
\hline & $163.69 / 164.79$ & 1.07 & 16.62 & $\mathrm{~S}_{\mathrm{n}}{ }^{2-} / \mathrm{S}^{0}$ \\
\hline \multirow{5}{*}{ Chalcopyrite $+\mathrm{Cu}+\mathrm{STG}$} & $161.24 / 162.34$ & 0.83 & 30.70 & $\mathrm{~S}^{2-}$ \\
\hline & $161.88 / 162.98$ & 1.25 & 39.36 & $\mathrm{C}-\mathrm{SCu}$ \\
\hline & $162.64 / 163.91$ & 1.41 & 17.14 & $\mathrm{~S}_{2}{ }^{2-}$ \\
\hline & $163.32 / 164.62$ & 0.90 & 5.35 & $\mathrm{~S}^{2-} / \mathrm{S}^{0}$ \\
\hline & $168.44 / 169.74$ & 1.51 & 4.47 & $\mathrm{SO}_{4}^{2-}$ \\
\hline
\end{tabular}

It should be noted that with the $\mathrm{CuSO}_{4}$ and STG treatment, the band of the $\mathrm{C}-\mathrm{SCu}$ bond also witnessed a significant shift from $162.03 \mathrm{eV}$ to $161.88 \mathrm{eV}$, implying that the $\mathrm{CuSO}_{4}$ could interact with the STG on the chalcopyrite surface. Under this reagent condition, the $\mathrm{SO}_{4}^{2-}$ concentration on the chalcopyrite decreased from $7.36 \%$ to $4.47 \%$, which agrees well with the above auxiliary effect. The addition of the $\mathrm{CuSO}_{4}$ induced a certain drop in the $\mathrm{S}_{\mathrm{n}}{ }^{2-} / \mathrm{S}^{0}$ concentration (from $16.62 \%$ to $5.94 \%$ ) on the chalcopyrite surface and resulted in the auxiliary depressant effect of the STG [15].

Figure 7 shows the $\mathrm{Cu} 2 \mathrm{p} 3 / 2$ XPS spectra of the chalcopyrite with treatment of different flotation reagents. The XPS bands at $932.05 \mathrm{eV}$ was attributed to cuprous $[15,16,18]$. The XPS bands at 933.26 $\mathrm{eV}$ were attributed to copper sulfide $\mathrm{Cu}-\mathrm{S}[15,16,18]$ by the oxidation process of cuprous on the chalcopyrite surface. It can be seen that the copper species included chalcopyrite and copper sulfide on the chalcopyrite surface, and the copper on the chalcopyrite surface only was monovalent.

With copper ion treatment (see Figure $7 \mathrm{~b}$ ), copper species and their proportion on the chalcopyrite sample surface were changed. It can be seen that a new $\mathrm{Cu} 2 \mathrm{p} 3 / 2$ peak appeared at $934.40 \mathrm{eV}$ due to the cupric oxides/hydroxides $[19,20]$. The copper concentration in chalcopyrite decreased largely from $65.30 \%$ to $3.36 \%$, indicating that a large quantity of copper ions were adsorbed on the chalcopyrite sample surface. At the same time, the copper concentration in copper sulfide increased largely from $34.70 \%$ to $51.66 \%$ on the chalcopyrite sample surface, indicating that the added $\mathrm{CuSO}_{4}$ successfully changed allocation proportion of copper species. In the pulp, iron first dissolved on the chalcopyrite surface [21-23], which is consistent with previous reports. Therefore, some surface defects were formed on the surface of chalcopyrite. After adding $\mathrm{CuSO}_{4}$, a part of copper ions could fill these surface defects and finally form copper sulfide or cupric oxides/hydroxides.

Figure 7c shows the XPS band of the chalcopyrite with the treatment of STG. It can be seen that a new $\mathrm{Cu} 2 \mathrm{p} 3 / 2$ peak appeared at $932.49 \mathrm{eV}$, suggesting that the STG had chemically adsorbed on the chalcopyrite sample surface, mainly through the Cu-STG complex [24,25]. The copper concentration in chalcopyrite decreased from $65.30 \%$ to $52.04 \%$, while the copper concentration in copper sulfide decreased largely from $34.70 \%$ to $16.62 \%$ on the chalcopyrite sample surface, indicating that STG was more easily adsorbed on copper sulfide. However, with the $\mathrm{CuSO}_{4}+\mathrm{STG}$ treatment (see Figure 7d), the Cu-STG complex concentration significantly increased from $31.34 \%$ to $68.15 \%$, indicating that the addition of copper ions could contribute to the adsorption of STG. and the depression of chalcopyrite was realized by the hydrophilic group $\left(-\mathrm{COO}^{-}\right)$in the STG. At the same time, the $\mathrm{Cu}^{2+}-\mathrm{O} / \mathrm{OH}$ concentration decreased from $44.98 \%$ to $15.26 \%$. The above results strongly prove that the addition of copper ions increased the reaction sites on the surface of chalcopyrite and exhibited an auxiliary effect with STG on the chalcopyrite inhibition. 

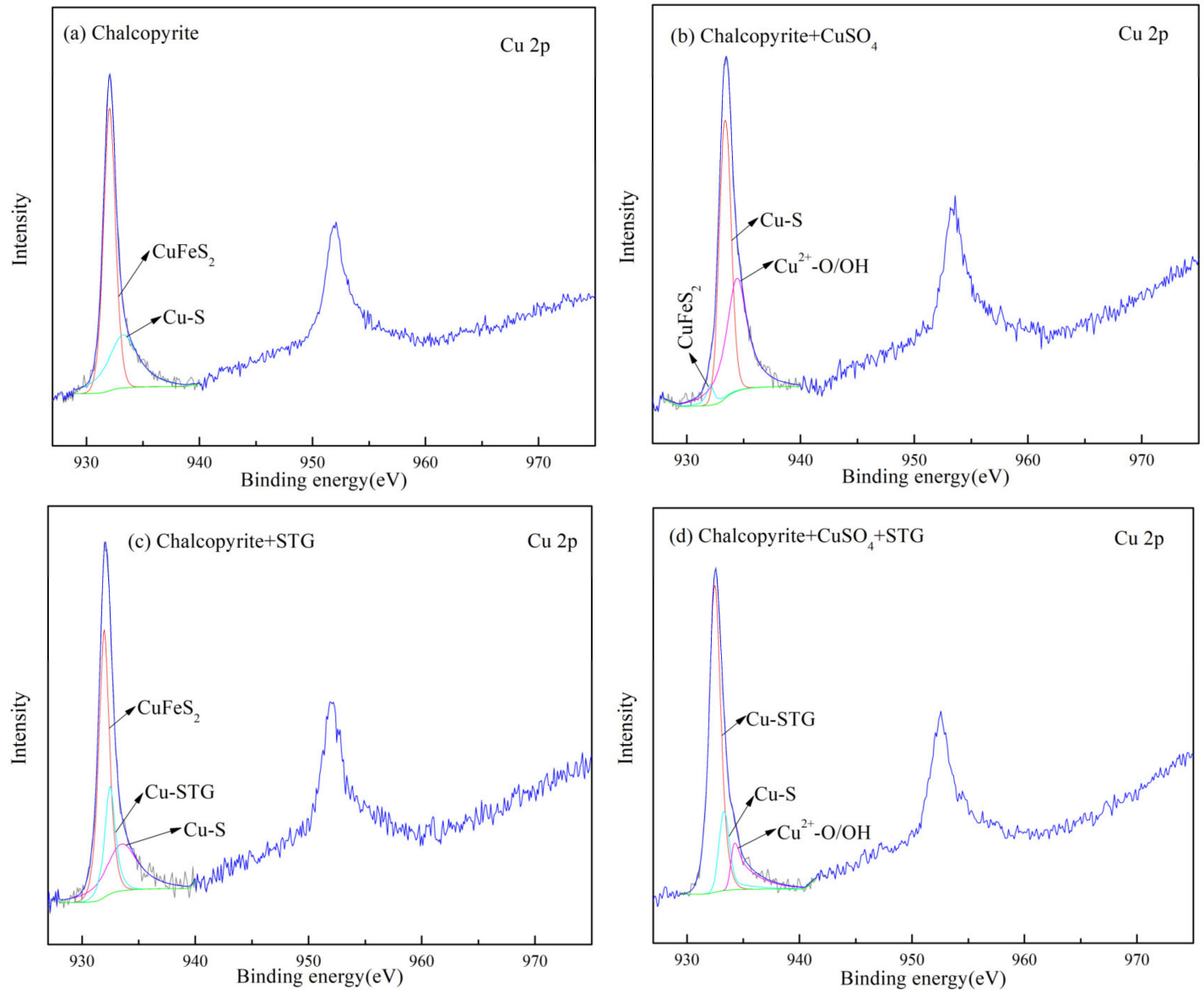

Figure 7. $\mathrm{Cu} 2 \mathrm{p}$ XPS spectra of chalcopyrite (a), chalcopyrite $+\mathrm{CuSO}_{4}(\mathbf{b})$, chalcopyrite $+\mathrm{STG}(\mathbf{c})$ and chalcopyrite $+\mathrm{CuSO}_{4}+\mathrm{STG}(\mathrm{d}) ;\left(\mathrm{c}\left(\mathrm{CuSO}_{4}\right)=1 \times 10^{-3} \mathrm{~mol} / \mathrm{L}, \mathrm{c}(\mathrm{STG})=1.5 \times 10^{-3} \mathrm{~mol} / \mathrm{L}\right)$.

Table 3. The parameters and assignment of high-resolution $\mathrm{Cu} 2 \mathrm{p} 3 / 2$ XPS spectra.

\begin{tabular}{ccccc}
\hline Species & Binding Energy/eV & FWHM/eV & Percentage/\% & Assignment \\
\hline \multirow{2}{*}{ Chalcopyrite } & 932.05 & 1.27 & 65.30 & $\mathrm{CuFeS}_{2}$ \\
& 933.26 & 3.17 & 34.70 & $\mathrm{CuS}$ \\
\hline \multirow{3}{*}{ Chalcopyrite $+\mathrm{Cu}$} & 932.06 & 0.79 & 3.36 & $\mathrm{CuFeS}_{2}$ \\
& 933.24 & 1.23 & 51.66 & $\mathrm{CuS}$ \\
& 934.40 & 2.16 & 44.98 & $\mathrm{Cu}^{2+}-\mathrm{O} / \mathrm{OH}$ \\
\hline \multirow{3}{*}{ Chalcopyrite + STG } & 931.94 & 1.05 & 52.04 & $\mathrm{CuFeS}_{2}$ \\
& 932.49 & 1.28 & 31.34 & $\mathrm{Cu}-\mathrm{STG}$ \\
Chalcopyrite $+\mathrm{Cu}+\mathrm{STG}$ & 933.78 & 2.10 & 16.62 & $\mathrm{CuS}$ \\
& 932.44 & 1.21 & 68.15 & $\mathrm{Cu}-\mathrm{STG}$ \\
& 933.30 & 1.10 & 16.60 & $\mathrm{CuS}$, \\
& 934.22 & 1.37 & 15.26 & $\mathrm{Cu}^{2+}-\mathrm{O} / \mathrm{OH}$ \\
\hline
\end{tabular}

\subsection{FTIR Studies}

The FTIR spectra of chalcopyrite with and without $\mathrm{CuSO}_{4}$ and STG treatment were presented in Figure 8. The functional groups of STG are shown in Figure 8e. The two bands with peaks at around $1593 \mathrm{~cm}^{-1}$ and $1416 \mathrm{~cm}^{-1}$ represent the antisymmetric $\left(\nu_{\mathrm{as}}\left(\mathrm{COO}^{-}\right)\right)[4,26,27]$ and symmetric $\left(v_{\mathrm{S}}\left(\mathrm{COO}^{-}\right)\right)[4,26,27]$ stretching bands of carboxyl groups of STG, respectively. The bands at around $658 \mathrm{~cm}^{-1}$ [28] and $2554 \mathrm{~cm}^{-1}$ [29] were due to the C-S and S-H stretching vibration, respectively.

With the STG and $\mathrm{CuSO}_{4}+\mathrm{STG}$ treatment, several peaks appeared on the surface of chalcopyrite, as shown in Figure $8 \mathrm{f}$, e. The band at around $668 \mathrm{~cm}^{-1}$ was due to the $\mathrm{C}-\mathrm{S}$ stretching vibration. 
The bands at around $1635 \mathrm{~cm}^{-1}$ and $1385 \mathrm{~cm}^{-1}$ represent the antisymmetric $\left(v_{\mathrm{as}}\left(\mathrm{COO}^{-}\right)\right)$and symmetric $\left(v_{\mathrm{S}}\left(\mathrm{COO}^{-}\right)\right)$stretching bands, respectively. Meanwhile, the S-H stretching vibration peak vanished, while $C-S$ stretching vibration peak was still presented. These changes in the FTIR spectra indicate that STG was successfully chemical adsorbed on chalcopyrite surfaces.

Figure $8 \mathrm{~d}$ shows the FTIR difference spectrum of Figure $8 \mathrm{f}$,e. The characteristic peaks of C-S and $\mathrm{COO}^{-}$were both still presented, indicating the adsorption quantity of STG increased after the $\mathrm{CuSO}_{4}$ treatment. Therefore, more hydrophilic groups covered the chalcopyrite surface and increased the depressant effect on the chalcopyrite flotation with STG.

The results described above show that it is obvious that copper ions can be adsorbed on the chalcopyrite surface, which resulted in significant changes in the type and proportion of copper and increased the reaction sites of the chalcopyrite surface. With copper ion treatment, the copper concentration in chalcopyrite decreased largely, while the copper concentration in copper sulfide increased largely on the chalcopyrite sample surface. In addition, the adsorption capacity of STG on copper sulfide was stronger than that on chalcopyrite which caused more STG to adsorb on the chalcopyrite sample surface. At the same time, the decrease of $S n^{2-} / S^{0}$ concentration further improved the hydrophilia of chalcopyrite, and the increase of the Zeta potential made the electrostatic repulsion of chalcopyrite surface with STG decrease, which made STG interact with chalcopyrite easier.
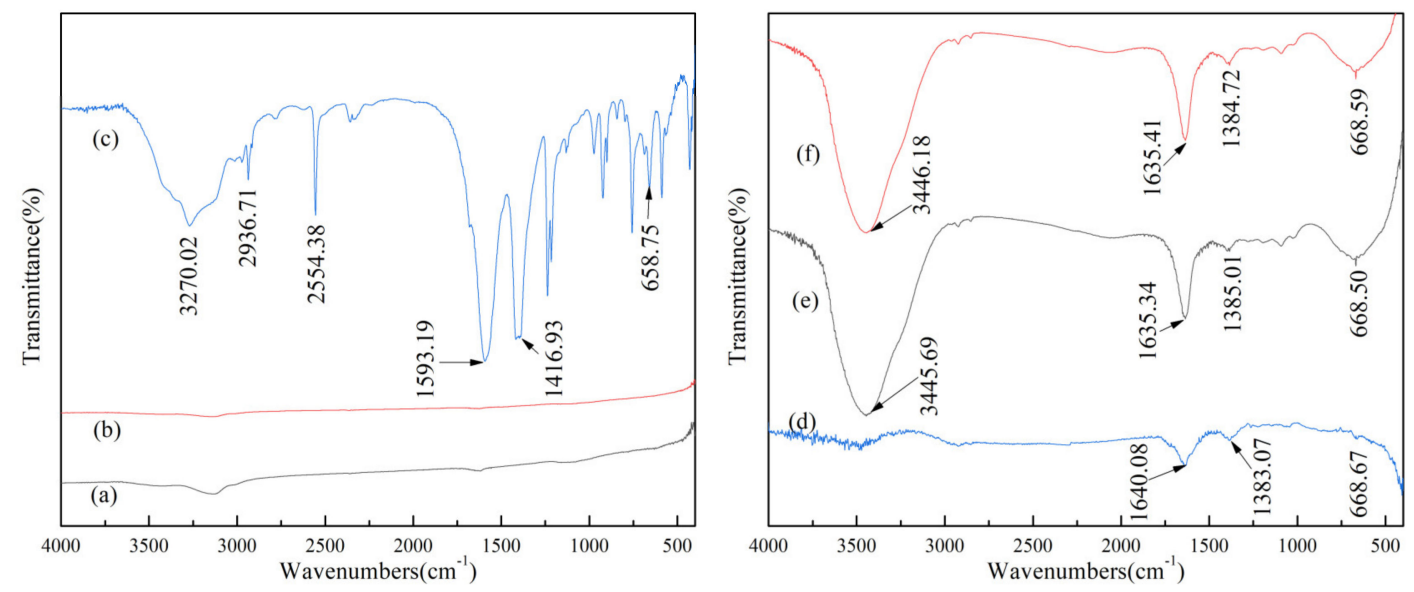

Figure 8. The FTIR spectra of chalcopyrite (a), chalcopyrite $+\mathrm{CuSO}_{4}(\mathbf{b}), \mathrm{STG}(\mathbf{c})$, difference spectrum (d), chalcopyrite $+\mathrm{STG}(\mathbf{e})$, and chalcopyrite $+\mathrm{CuSO}_{4}+\mathrm{STG}(\mathbf{f}) ; \mathrm{c}\left(\mathrm{CuSO}_{4}\right)=1 \times 10^{-3} \mathrm{~mol} / \mathrm{L}, \mathrm{c}(\mathrm{STG})=$ $1.5 \times 10^{-3} \mathrm{~mol} / \mathrm{L}$.

\section{Conclusions}

In this paper, STG was introduced as a depressant on chalcopyrite flotation. The copper ions were proved to exhibit an auxiliary effect on the depressant effect of STG when xanthate was used as a collector. Copper ions can adsorb on the surface of chalcopyrite and increase the reaction sites on the surface of chalcopyrite. These increased active sites could allow the absorption of more sodium thioglycolate on the particle surface and could result in the enhancement of chalcopyrite depression.

Author Contributions: Conceptualization, C.Z. and T.H.; methodology, C.Z.; formal analysis, X.B.; investigation, S.W.; data curation, T.H. and W.C.; writing-original draft preparation, C.Z.; writing—review and editing, C.Z. and W.C.; supervision, X.T. All authors have read and agreed to the published version of the manuscript.

Funding: This research was funded by the National Natural Science Foundation of China(Grant Nos. 51674184 and 51904221); the Open Foundation of State Key Laboratory of Mineral Processing (Grant No. BGRIMM-KJSKL-2020-05); the General Project (Youth) of Natural Science Basic Research funded by Shaanxi Science and Technology Department (Grant Nos. 2019JQ-468 and 2019JQ-368); the China Postdoctoral Science Foundation Funded Project (Grant Nos. 2018M640964 and 2019T120884), the Natural Science Project of Shaanxi Education Department (Grant No. 19JK0465), the Special Research Project of Shan Xi Education Department (Grant No.18JK0473).

Conflicts of Interest: The authors declare no conflict of interest. 


\section{References}

1. Córdoba, E.M.; Muñoz, J.A.; Blázquez, M.L.; González, F.; Ballester, A. Hydrometallurgy Leaching of chalcopyrite with ferric ion. Part I: General aspects. Hydrometallurgy 2008, 93, 81-87. [CrossRef]

2. Pearse, M.J. An overview of the use of chemical reagents in mineral processing. Miner. Eng. 2005, 18, 139-149. [CrossRef]

3. Zhang, C.; Li, L.; Yuan, Z.; Xu, X.; Song, Z.; Zhang, Y.R. Mechanical properties of siderite and hematite from DFT calculation. Miner. Eng. 2019, 146, 106107. [CrossRef]

4. Liu, Y.; Liu, Q. Flotation separation of carbonate from sulfide minerals, II: Mechanisms of flotation depression of sulfide minerals by thioglycollic acid and citric acid. Miner. Eng. 2004, 17, 865-878. [CrossRef]

5. Tadie, M.; Corin, K.C.; Wiese, J.G.; O'Connor, C.T. Electrochemical interactions of platinum group minerals with copper sulphate. Miner. Eng. 2017, 112, 43-49. [CrossRef]

6. Feng, B.; Zhong, C.; Zhang, L.; Guo, Y.; Wang, T.; Huang, Z. Effect of surface oxidation on the depression of sphalerite by locust bean gum. Miner. Eng. 2020, 146, 106142. [CrossRef]

7. Chandra, A.P.; Gerson, A.R. A review of the fundamental studies of the copper activation mechanisms for selective fl otation of the sul fi de minerals, sphalerite and pyrite. Adv. Colloid Interface Sci. 2009, 145, 97-110. [CrossRef]

8. Zhao, Q.; Liu, W.; Wei, D.; Wang, W.; Cui, B.; Liu, W. Effect of copper ions on the fl otation separation of chalcopyrite and molybdenite using sodium sul fi de as a depressant. Miner. Eng. 2018, 115, 44-52. [CrossRef]

9. Cao, Q.; Chen, X.; Feng, Q.; Wen, S. Activation mechanism of lead ion in the fl otation of stibnite. Miner. Eng. 2018, 119, 173-182. [CrossRef]

10. Fu, Y.; Zhu, Z.; Yao, J.; Han, H.; Yin, W.; Yang, B. Improved depression of talc in chalcopyrite flotation using a novel depressant combination of calcium ions and sodium lignosulfonate. Colloids Surfaces A 2018, 558, 88-94. [CrossRef]

11. Liu, C.; Zhu, G.; Song, S.; Li, H. Flotation separation of smithsonite from quartz using calcium lignosulphonate as a depressant and sodium oleate as a collector. Miner. Eng. 2019, 131, 385-391. [CrossRef]

12. Feng, Q.; Zhao, W.; Wen, S. Applied Surface Science Surface modification of malachite with ethanediamine and its effect on sulfidization flotation. Appl. Surf. Sci. 2018, 436, 823-831. [CrossRef]

13. Jia, Y.; Huang, K.; Wang, S.; Cao, Z.; Zhong, H. The selective fl otation behavior and adsorption mechanism of thiohexanamide to chalcopyrite. Miner. Eng. 2019, 137, 187-199. [CrossRef]

14. Yao, J.; Xue, J.; Yin, W.; Chu, W.; Zhu, Z.; Yang, B. Recovery of digenite from heavily oxidized Cu-S ore using $\mathrm{Na} 2 \mathrm{~S}$ as an activator. Miner. Eng. 2019, 134, 317-324. [CrossRef]

15. Cao, Z.; Chen, X.; Peng, Y. The role of sodium sul fi de in the fl otation of pyrite depressed in chalcopyrite $\mathrm{fl}$ otation. Miner. Eng. 2018, 119, 93-98. [CrossRef]

16. Zhao, H.; Wang, J.; Gan, X.; Hu, M.; Zhang, E.; Qin, W.; Qiu, G. Cooperative bioleaching of chalcopyrite and silver-bearing tailing by mixed moderately thermophilic culture: An emphasis on the chalcopyrite dissolution with XPS and electrochemical analysis. Miner. Eng. 2015, 81, 29-39. [CrossRef]

17. Jürgensen, A.; Raschke, H.; Esser, N.; Hergenröder, R. Applied Surface Science An in situ XPS study of L-cysteine co-adsorbed with water on polycrystalline copper and gold. Appl. Surf. Sci. 2018, 435, 870-879. [CrossRef]

18. Ghahremaninezhad, A.; Dixon, D.G.; Asselin, E. Electrochemical and XPS analysis of chalcopyrite (CuFeS2) dissolution in sulfuric acid solution. Electrochim. Acta 2013, 87, 97-112. [CrossRef]

19. Yang, B.; Wang, D.; Wang, T.; Zhang, H.; Jia, F.; Song, S. Effect of $\mathrm{Cu}^{2+}$ and $\mathrm{Fe}^{3+}$ on the depression of molybdenite in fl otation. Miner. Eng. 2019, 130, 101-109. [CrossRef]

20. Lu, J.; Tong, Z.; Yuan, Z.; Li, L. Investigation on fl otation separation of chalcopyrite from arsenopyrite with a novel collector: N-Butoxycarbonyl-O-Isobutyl Thiocarbamate. Miner. Eng. 2019, 137, 118-123. [CrossRef]

21. Qin, W.; Jiao, F.; Sun, W.; He, M.; Huang, H. Selective flotation of chalcopyrite and marmatite by MBT and electrochemical analysis. Ind. Eng. Chem. Res. 2012, 51, 11538-11546. [CrossRef]

22. Zeng, W.; Qiu, G.; Chen, M. Hydrometallurgy Investigation of $\mathrm{Cu}-\mathrm{S}$ intermediate species during electrochemical dissolution and bioleaching of chalcopyrite concentrate. Hydrometallurgy 2013, 134-135, 158-165. [CrossRef] 
23. Yang, Y.; Harmer, S.; Chen, M. Synchrotron-based XPS and NEXAFS study of surface chemical species during electrochemical oxidation of chalcopyrite. Hydrometallurgy 2015, 156, 89-98. [CrossRef]

24. Liu, S.; Liu, G.; Zhong, H.; Yang, X. Journal of Industrial and Engineering Chemistry The role of HABTC' s hydroxamate and dithiocarbamate groups in chalcopyrite fl otation. J. Ind. Eng. Chem. 2017, 52, 359-368. [CrossRef]

25. Plackowski, C.; Bruckard, W.J.; Nguyen, A.V. Surface characterisation, collector adsorption and flotation response of enargite in a redox potential controlled environment. Miner. Eng. 2014, 65, 61-73. [CrossRef]

26. Sritham, E.; Gunasekaran, S. Food Hydrocolloids FTIR spectroscopic evaluation of sucrose-maltodextrin-sodium citrate bioglass. Food Hydrocoll. 2017, 70, 371-382. [CrossRef]

27. Kets, E.P.W.; Ijpelaar, P.J.; Hoekstra, F.A.; Vromans, H. Citrate increases glass transition temperature of vitrified sucrose preparations. Cryobiology 2004, 48, 46-54. [CrossRef]

28. Sadat, F.; Rezai, B.; Kowsari, E. The main factors effecting the ef fi ciency of Zn (II) flotation: Optimum conditions and separation mechanism. J. Environ. Manag. 2018, 207, 169-179.

29. Yin, Z.; Xu, L.; He, J.; Wu, H.; Fang, S.; Ahmed, S.; Hu, Y.; Sun, W. Evaluation of L -cysteine as an eco-friendly depressant for the selective separation of MoS 2 from PbS by fl otation. J. Mol. Liq. 2019, 282, 177-186. [CrossRef]

(C) 2020 by the authors. Licensee MDPI, Basel, Switzerland. This article is an open access article distributed under the terms and conditions of the Creative Commons Attribution (CC BY) license (http://creativecommons.org/licenses/by/4.0/). 